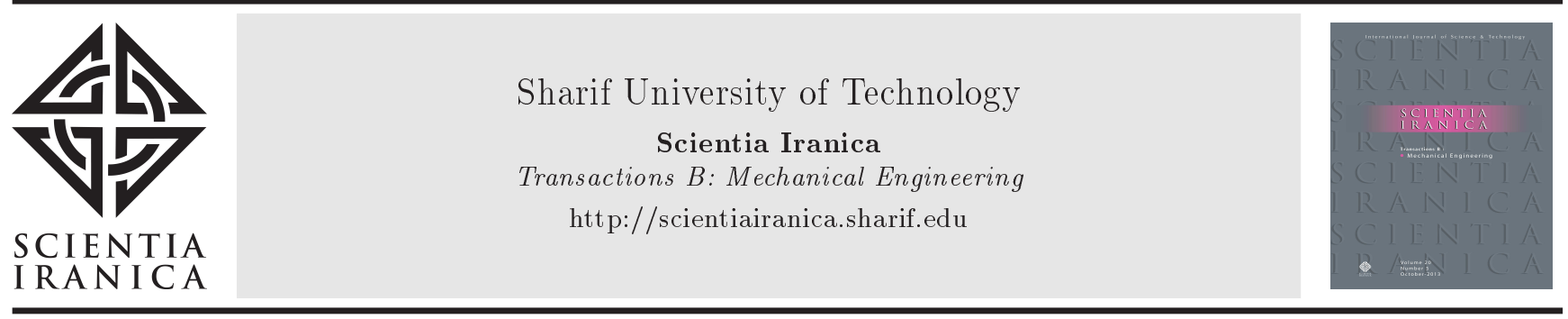

\title{
Sensitivity analysis and optimization of the surface roughness in the incremental forming of mild steel sheets
}

\author{
M.H. Shojaeefard ${ }^{\mathrm{a}, *}$, A. Khalkhali ${ }^{\mathrm{b}}$, and Sh. Shahbaz \\ a. Department of Mechanical Engineering, Iran University of Science and Technology, Tehran, Iran. \\ b. Automotive Simulation and Optimal Design Research Laboratory, School of Automotive Engineering, Iran University of Science \\ and Technology, Tehran, Iran.
}

Received 30 May 2019; received in revised form 2 August 2019; accepted 12 January 2020

\section{KEYWORDS \\ Mild steel sheet; \\ Surface roughness; \\ Single-point \\ incremental forming; \\ Taguchi technique; \\ ANOVA.}

\begin{abstract}
Flexibility and simple tooling make the Incremental Sheet Forming (ISF) a great process to create complex shapes from mild steel sheets. It is a significant issue to reduce the Surface Roughness (SR) which is an improper characteristic in the manufacturing of the mild steel parts in ISF process. SR has an adverse effect on the esthetic aspects of the mild steel products or their painting appearance. The purpose of this study is to investigate the effects of the ISF process parameters on the SR of the mild steel sheets. Feed rate, tool diameter, vertical step and spindle speed are chosen as four input variables for experimental tests. The Taguchi design of experiment and analysis of variance (ANOVA) are used to optimize the SR by investigating the parameters effects and their interactions. According to the obtained results, the vertical step reduction and increase in tool diameter, decrease the surface roughness of the mild steel sheets during the single-point incremental forming. In addition, the tool speed (rotation and feed) has little effect on the SR. The results of a validation test demonstrate that the Taguchi technique and the ANOVA effectively optimize the level of each variable to ensure the best SR.
\end{abstract}

(C) 2021 Sharif University of Technology. All rights reserved.

\section{Introduction}

Incremental sheet forming is an innovative method of sheet forming. In this way, the sheets are formed without a need for punches and related dies, in spite of being utilized in typical stamping processes. Therefore, ISF is taken as competitive alternative for economically manufacturing low-volume productions. For instance, one application of this process can be found in the

\footnotetext{
*. Corresponding author.

E-mail addresses: mhshf@iust.ac.ir (M.H. Shojaeefard);

Ab.Khalkhali@iust.ac.ir (A. Khalkhali);

Piau.shahbaz@gmail.com (Sh.Shahbaz)
}

doi: $10.24200 /$ sci.2020.53513.3274 automobile industry for producing car body panels of concept vehicles or special cars, made by the mild steel sheets. Other applications is in aerospace industry to manufacture the elements of an aircraft, and in medical industry to produce implants or medical devices. The process starts with incremental traveling of the hemispherical tool tip into the surface of sheet. The motion path is assumed to be characterized by G-codes in terms of Cartesian coordinates, derived from a Computer-Aided Design and Computer-Aided Manufacturing (CAD/CAM) software. Two methods of ISF are Single-Point Incremental Forming (SPIF) and Two-Point Incremental Forming (TPIF). Jeswiet and Hagan [1], Leach et al. [2], and Filice et al. [3] have been pioneers in developing the SPIF (Figure 1(a)). In this type of ISF, a free, unsupported surface is detected 


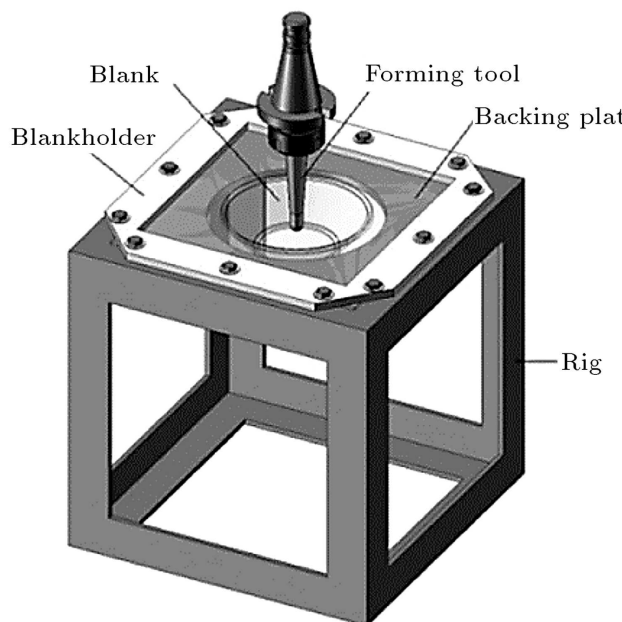

(a)

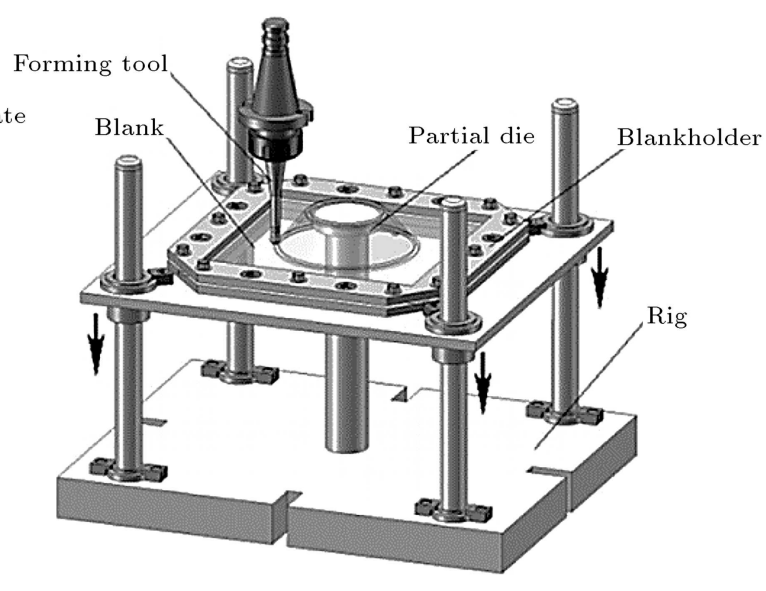

(b)

Figure 1. (a) Single-Point Incremental Forming (SPIF). (b) Two-Point Incremental Forming (TPIF) [6].

on the back of the formed sheet. Therefore, there would be just one point between the formed sheet and the tool tip. Powell and Andrew [4] and Matsubara [5] introduced the TPIF. In TPIF, as shown in Figure 2(b), there are two points which may cause the metal sheets to be deformed. The first point (similar to the SPIF), is the forming tool which causes the sheets' plastic deformation to be created. The second point is a supported die, located under the blank to facilitate the plastic deformation procedure, this is particularly true of forming complex shapes.

Mild steel or low-carbon steel blanks are the most typical form of steel and are commonly used in industry due to their low-cost constituent materials and properties that fit many applications. Surface roughness control of this kind of steel sheets is a critical requirement for producing different parts through SPIF process. The surface roughness of mild steel sheets is the main cause of a phenomenon called orange peel. It is a kind of textured imperfection in the painting process. This imperfection causes the aesthetic aspects of the painted mild steel samples to be disfigured.
Therefore, it is important to analysis and optimize the SR of the mild steel samples, formed by the SPIF. However, previous studies have investigated the surface roughness of materials rather than that of mild steel sheets. Hagan and Jeswiet [7] used a white light interferometry scan to perform surface roughness analysis of the SPIF test using the annealed Al3003 sheets. It was seen that increasing the step of the tool pitch, the $R_{z}$ increased. Cerro et al. [8] conducted some experimental tests and used Finite Element Method (FEM) simulations to evaluate the SR of the Al1050-0 sheets. The results showed that the surface roughness decreased by reducing the axial step size. Durante et al. [9] evaluated the direction and speed of tool rotation in the ISF of the Al7075-T0 sheets.

These findings showed that, considering the influence of the tool rotation, the roughness value differs both in terms of rotary speed and direction of the tool rotation. Hamilton and Jeswiet [10] investigated the effect of tool's high rotational speed and feed rate on the SPIF processing of the Al3003-H14 sheets. Bhattacharya et al. [11] conducted an experimental research

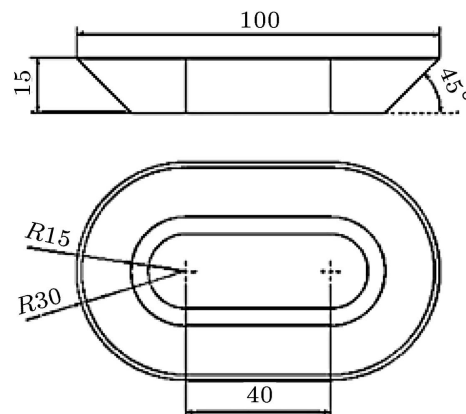

(a)

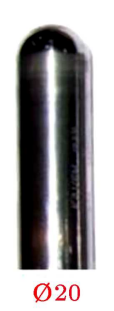

(b)
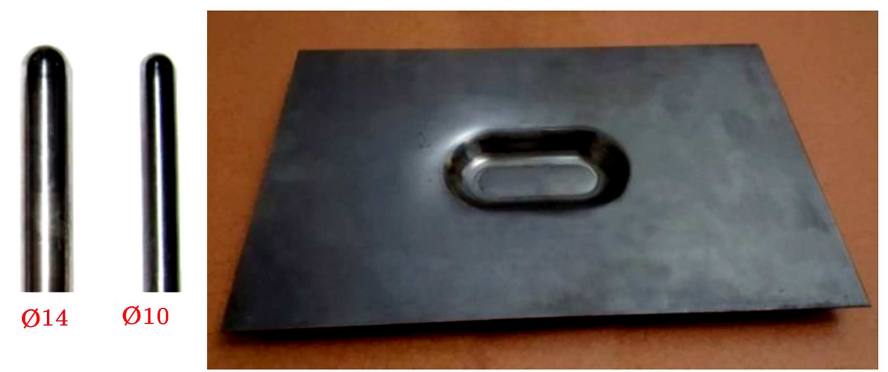

(c)

Figure 2. (a) The main dimensions of the elongated hole, used as the shape of the process (mm). (b) Tungsten Carbide hemispherical forming tools used in the forming process of the mild steel sheets $(\mathrm{mm})$. (c) Final elongated cone formed on the mild steel sheet during the Single-Point Incremental Forming (SPIF). 
on the Al5052. They explained that the SR value decreased as the tool size and wall angle increased. $\mathrm{Lu}$ et al. [12] investigated the friction effect on the surface finish by using the traditional rigid tool and oblique roller-ball tool. Four types of aluminum sheet, i.e., Al1100, Al2024, Al5052, and Al6111, were used in their study. It was demonstrated that the oblique tool could create a better surface on the samples. Echrif and Hrairi [13] utilized the Al1050-O sheets in their SPIF tests. They used Taguchi technique and ANOVA to investigate and optimize the quality of the surface of Al sheets. They proved that tool's large diameter, accompanied by its low vertical movement, caused a smoother surface to be created in the formed specimen. Gulati et al. [14] optimized both SR and formability of the Al6063 sheets. They performed some SPIF tests using the Taguchi's $L_{18}$ orthogonal array. Based on their findings, the surface roughness is positively affected by lubrication, feed rate, tool radius, step size, sheet thickness, and tool rotational speed. Yao et al. [15] studied the effects of tool diameter, step down, wall angle, and initial sheet thickness on the deformation energy, SR, and dimensional errors of the Al1060 sheets. The results showed that the most important parameter that influenced the surface roughness was the step down. Taherkhani et al. [16], using the Al3105 sheets, performed four process parameters to model the Group Method of Data Handling (GMDH) as a sub model of artificial neural networks. Asghari et al. [17] studied the surface quality of Al1050 sheets during the TPIF process. Performing multiobjective optimization through grey relational analysis, they found that the main indicators of optimum condition include: minimum thickness, surface quality, and springback. The above-mentioned papers failed to present a convincing and systematic method to analysis and optimize all SR's process parameters of the of mild steel parts, produced in the SPIF process. Due to its interesting mechanical characteristics, the mild steel's application prevalent in different forming methods, including the incremental forming,. Hence, surface roughness analysis and optimization seem necessary for these kinds of steel sheets in the SPIF.

The SR received a great deal of importance in terms of the quality of the mild steel blanks formed in the ISF process. This research investigates the effects of main process variables on the surface roughness of mild steel blanks, resulting from the SPIF process of an elongated cone. Feed rate, tool diameter, vertical step and spindle speed were taken as the main parameters of the experiments. Using a surface profile meter, the arithmetic average roughness $\left(R_{a}\right)$ parameter is considered to measure the surface roughness. Sixteen experimental tests are presented according to the Taguchi Design Of Experiment (DOE) and the analysis of variance (ANOVA). The purpose was to study the effects of input factors on the process parameters optimization and to obtain the lowest roughness of the mild steel sheet in the SPIF of an elongated cone. Finally, the specimen results from the optimized parameters are confirmed by a validation experiment.

\section{Experimental tests}

The sheet metal used in this study is the DIN St12, a mild steel sheet. Dimensions and thickness of the initial blanks are $250 \mathrm{~mm} \times 160 \mathrm{~mm}$ and $1 \mathrm{~mm}$, respectively. This material has good formability and high tensile strength. Mechanical properties and chemical composition of the St12 sheets are presented in Table 1.

It is assumed that an elongated cone is created on the initial blank. The main dimensions of the shape are shown in Figure 2(a). As shown in Figure 2(b), the Tungsten Carbide forming tool is characterized by a hemispherical tip. During sheet forming in the SPIF, the tool tip wears and some small parts of the tool head may even become separated due to the local tool-sheet contact and the resulting friction between them. This has a negative effect on the forming surface quality. Hence, it is so important to choose an appropriate material with enough strength to guarantee a proper contact between tool and steel sheet. Generally, a Tungsten Carbide has a hardness value of about $1600 \mathrm{HV}$, while the hardness value of mild steel is approximately $160 \mathrm{HV}$. Consequently, Tungsten Carbide is approximately wearresistant when contacting the steel sheet and exhibits enough resistance against friction, so the temperature increases during the process of sheet deformation. The Tungsten Carbide tool follows a Z-level path (pattern) to form the elongated cone based on the G-codes generated by the $\mathrm{CAD} / \mathrm{CAM}$ software. During the movement of the tool, the SAE40 is used as lubricant. It is clear that the lubrication decreases the surface roughness because of the friction reduction at the

Table 1. Chemical composition and mechanical properties of St12 sheets utilized in the Single-Point Incremental Forming (SPIF) process.

\begin{tabular}{|c|c|c|c|c|c|c|c|}
\hline \multirow{3}{*}{$\begin{array}{c}\text { Material } \\
\text { St12 }\end{array}$} & \multicolumn{4}{|c|}{$\begin{array}{c}\text { Chemical composition } \\
\text { (wt\%) }\end{array}$} & \multicolumn{3}{|c|}{ Mechanical properties } \\
\hline & $\mathrm{C}$ & Mn & $\mathbf{P}$ & $\mathrm{S}$ & YS (MPa) & UTS (MPa) & Elong. (\%) \\
\hline & 0.10 & 0.50 & $<0.05$ & $<0.05$ & 186 & 306 & 48 \\
\hline
\end{tabular}


Table 2. Input parameters and their levels in the Taguchi design of experiments ( 4 factors in 4 levels).

\begin{tabular}{lcccccc}
\hline \multirow{2}{*}{ Parameters } & \multirow{2}{*}{ Notation } & \multirow{2}{*}{ Unit } & \multicolumn{5}{c}{ levels } \\
\cline { 4 - 7 } & & & $\boldsymbol{L}_{\mathbf{4}}$ & $\boldsymbol{L}_{\mathbf{3}}$ & $\boldsymbol{L}_{\mathbf{2}}$ & $\boldsymbol{L}_{\mathbf{1}}$ \\
\hline Feed rate & $F$ & $\mathrm{~mm} / \mathrm{min}$ & 150 & 185 & 215 & 250 \\
Tool diameter & $D$ & $\mathrm{~mm}$ & 10 & 14 & 18 & 20 \\
Vertical step & $Z$ & $\mathrm{~mm}$ & 0.5 & 0.65 & 0.85 & 1 \\
Spindle speed & $W$ & $\mathrm{rpm}$ & 500 & 670 & 840 & 1000 \\
\hline
\end{tabular}

interface of tool and the blank, therefore its use leads to a better surface quality. The final formed blank is shown in Figure 2(c). Combining the effective parameters, Taguchi introduced a useful technique for optimizing the performance qualities, referred to as an engineering optimization method. To obtain the best design in terms of efficiency, quality, and total cost, Taguchi method gives an effective technique. This technique provides the finest parameters, through which the robust and high quality systems could be attained. The tests are performed using a Taguchi design as an highly applicable technique for controlling the production quality [18-20]. Input variables are the feed rate, spindle tool diameter and vertical step. The surface roughness of the mild steel sheet is assumed as to be the output parameter which is denoted by $R_{a}$. The levels of the considered parameters are shown in Table 2 .

\section{Method of the surface roughness measurement}

The surface integrity and topography constitutes the two main aspects of the surface quality. The surface integrity describes metallurgical and mechanical changes of the surface, created by machining operation. The surface topography deals with the geometry of the machined surfaces and includes the surface lay, roughness and waviness [21]. The main aspects of the surface topography in the ISF process are the surface waviness and roughness. During the SPIF, when the tool moves on the sheet, certain areas on the blank remain untouched, because of the tool's helical path. Therefore, the surface waviness forms in this area [22]. In addition, tool movement in a local zone on the blank during the SPIF results in the surface roughness. Roughness usually causes an orange peel phenomenon on the external surface of the specimens. It has a detrimental effect on the esthetic aspect of the products or the painting appearance. In this study, surface roughness is denoted by the arithmetic average surface roughness $\left(R_{a}\right)$. This parameter is established as the average deviation of the surface irregularities along a specific length. In fact, $R_{a}$ is integral of the roughness height over the desired section of the part and is defined by Eq. (1) [23]:

$$
R_{a}=\frac{1}{L} \int_{0}^{L}|Y(x)| d x
$$

where $Y$ is the ordinate of the roughness profile curve created on the formed blank during the process, and $L$ is the sampling length (see Figure 3 ).

Microscopes, stylus instruments, or even a standard device is used for visual or touching comparison, providing the possibility of SR's assessment in the industrial manufacturing. In the present study, to determine quickly and accurately the surface roughness of the formed blanks, a Mahr M1 (a stylus instrument) is used, as shown in Figure 4.

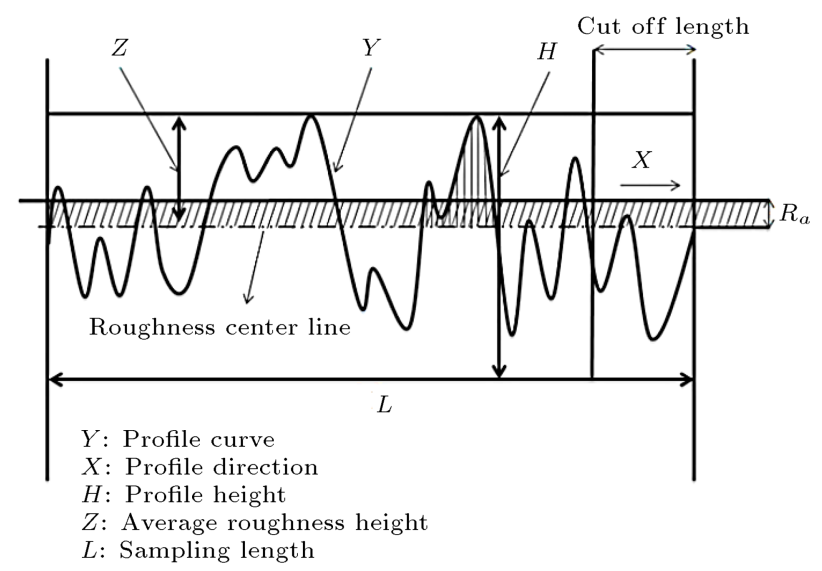

Figure 3. Surface roughness profile and average surface roughness $\left(R_{a}\right)$ definition [13].

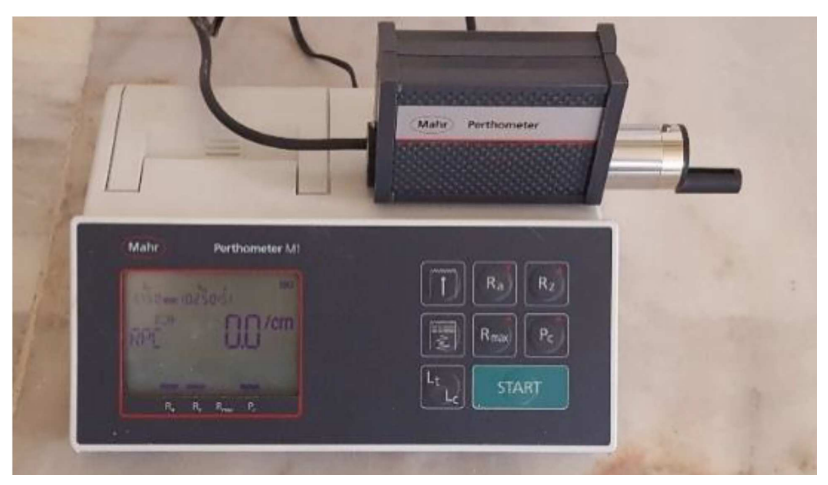

Figure 4. Mahr M1 used for $R_{a}$ measurement. 
Table 3. $L_{16}$ Taguchi orthogonal array designed for the roughness measurement on the mild steel sheets.

\begin{tabular}{cccccc}
\hline Experment & $\begin{array}{c}\boldsymbol{F} \\
(\mathbf{m m} / \mathbf{m i n})\end{array}$ & $\begin{array}{c}\boldsymbol{D} \\
(\mathbf{m m})\end{array}$ & $\begin{array}{c}\boldsymbol{Z} \\
(\mathbf{m m})\end{array}$ & $\begin{array}{c}\boldsymbol{W} \\
(\mathbf{r p m})\end{array}$ & $\begin{array}{c}\boldsymbol{R}_{\boldsymbol{a}} \\
(\boldsymbol{\mu} \mathbf{m})\end{array}$ \\
\hline 1 & 150 & 10 & 0.5 & 500 & 1.413 \\
2 & 185 & 10 & 0.65 & 670 & 1.422 \\
3 & 215 & 10 & 0.85 & 840 & 1.436 \\
4 & 250 & 10 & 1 & 1000 & 1.443 \\
5 & 150 & 14 & 0.85 & 670 & 1.437 \\
6 & 185 & 14 & 1 & 500 & 1.476 \\
7 & 215 & 14 & 0.5 & 1000 & 1.321 \\
8 & 250 & 14 & 0.65 & 840 & 1.366 \\
9 & 150 & 18 & 1 & 840 & 1.429 \\
10 & 185 & 18 & 0.85 & 1000 & 1.386 \\
11 & 215 & 18 & 0.65 & 500 & 1.352 \\
12 & 250 & 18 & 0.5 & 670 & 1.297 \\
13 & 150 & 20 & 0.65 & 1000 & 1.317 \\
14 & 185 & 20 & 0.5 & 840 & 1.278 \\
15 & 215 & 20 & 1 & 670 & 1.401 \\
16 & 250 & 20 & 0.85 & 500 & 1.378 \\
\hline
\end{tabular}

\section{Results}

$L_{16}$ Taguchi orthogonal array is adopted to investigate how the four input variables affect the SR of the mild steel sheets. The control factor values for each SPIF experiment are shown in Table 3 . In each experiment, the SR is measured in three different points of the internal surface of the elongated cone and the average of all measured $R_{a}$ is reported in Table 3 as the specimen roughness.

\subsection{Response graph and table}

The effect of input parameters on the output factor is shown in the means response table. This table is one of the most important tools of the Taguchi technique to meet the objectives in an engineering design. The means response table can specify which process parameter has the greatest impact on the response. In addition, the trend of each control factor can be observed. In other words, this table determines which level of the input variables is related to higher or lower response values. When the input parameters are changed, the response variations can be investigated using the main effect plot of the means. The means response table and the effect plot of means are illustrated in Table 4 and Figure 5. The ranks shown in Table 4 explain that the vertical step $(Z)$, standing at the top of the rankings, is the most effective process parameter for formed blanks' SR. The second rank belongs to the tool diameter $(D)$, followed by the tool rotational speed $(W)$ and the feed rate $(F)$, respectively.

An increase in the vertical step $(Z)$ results in the coarser surface roughness of the formed sheets. Table 4 depicts that $R_{a}$ increases from $1.327 \mu \mathrm{m}$ to $1.437 \mu \mathrm{m}$ over the step depth range of $0.5 \mathrm{~mm}$ to $1 \mathrm{~mm}$ (levels 1 to 4 in Table 1). By increasing the
Table 4. Table of responses for means of $R_{a}$ in the Single-Point Incremental Forming (SPIF) process of mild steel sheets.

\begin{tabular}{ccccc}
\hline Level & $\boldsymbol{F}$ & $\boldsymbol{D}$ & $\boldsymbol{Z}$ & $\boldsymbol{W}$ \\
\hline 1 & 1.399 & 1.429 & 1.327 & 1.405 \\
2 & 1.390 & 1.400 & 1.364 & 1.389 \\
3 & 1.377 & 1.366 & 1.409 & 1.377 \\
4 & 1.371 & 1.343 & 1.437 & 1.367 \\
Delta & 0.028 & 0.085 & 0.110 & 0.038 \\
Rank & 4 & 2 & 1 & 3 \\
\hline
\end{tabular}

vertical step, the axial force of the tool increases and a deeper micro valley will be created at the interface of the tool and the mild steel sample. Moreover, analysis of the samples showed that some regions of the sheet partially remained as micro peaks between the successive contours of each step during the tool vertical motion. Thus, micro peaks and valleys of the surface increase, making the surface rougher. Reduction of the tool vertical movement results in a more overlap among the neighbor contour paths, traced by the forming tool. Consequently, increasing the tool steps in the vertical dimension increases the SR in SPIF of the mild steel sheets; however, the process time reduces when the vertical step increases.

The diameter's increase of the hemispherical tool $(D)$ can affect appropriately the SR of the mild steel blanks. When the tool diameter size increases, $R_{a}$ of the final parts decreases. Increasing the tool diameter, the contact pressure at the interface of the tool and the blank decreases, yielding the uniform and flats patterns (micro peak and valleys). As a result, the surface roughness will decrease. Furthermore, surface roughness reduction through increasing the tool diameter could be considered as the result of the overlap zone increase between each contour of the tool path; this is 


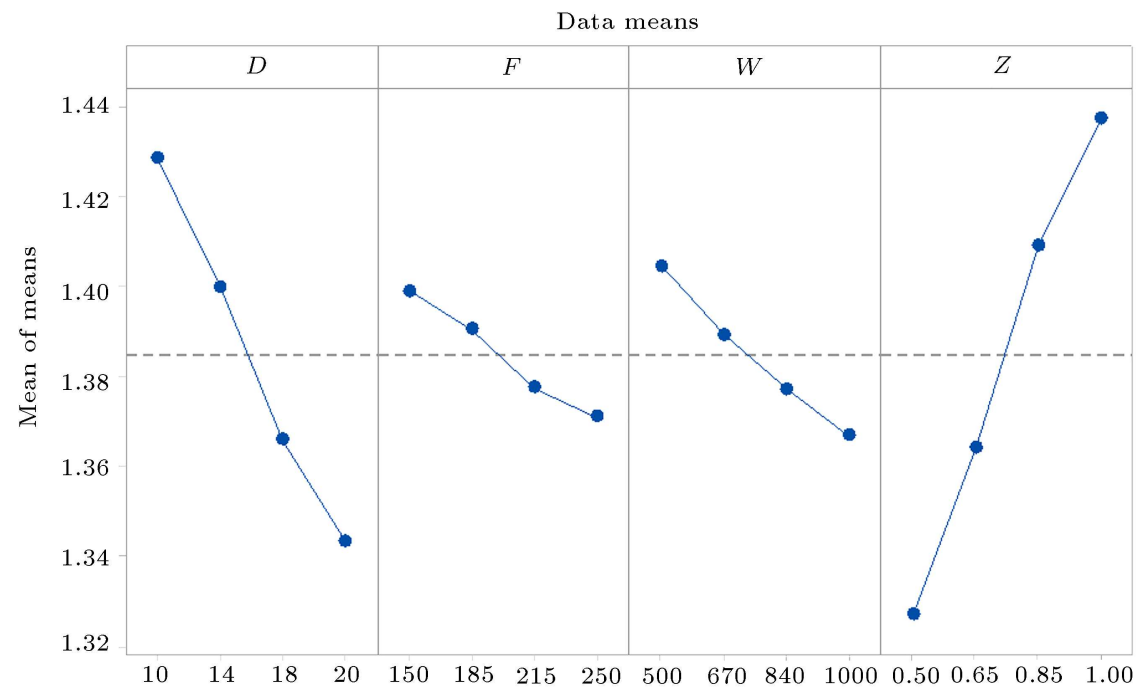

Figure 5. Main effect plots for means of $R_{a}$ of the mild steel sheets in the Single-Point Incremental Forming (SPIF) experiments.

due to the larger contact area between tool and blank. Therefore, the decrease of the forming tool's diameter causes the surface of the mild steel sheets to be rough; however, better formability could be achieved through increasing the tool diameter size.

As it is clear from Table 4 and Figure 5, through increasing the spindle speed $(W)$, the surface roughness could be reduced (due to the selected range of the tool rotational speeds shown in Table 1 ). By speeding up the spindle, the sliding friction at the interface of the tool tip and the specimen surface increases. As a result, the heat treatment increased in the forming process. In this way, contact area of the Tungsten Carbide tool and the mild steel sheet is changed from adhesive to abrasive type and the surface quality improved. Moreover, the rotation tool creates some veins on the blank, taken as the asperity of the surface. The increase of the spindle speed leads to the smaller veins creation, and the surface becomes more polished, reflecting the mild steel sheets' SR reduction. As shown in Table 4, the spindle speed effect on the SR of the SPIF experiments is negligible.

When the feed rate increases in the SPIF, $R_{a}$ decreases. In fact, higher feed rates associated with tool vibration in the experiments result in wear rate, friction, and temperature increase. One reason is that when the feed rate increases, the tools high speed prevents the lubricant film to be formed at the toolblank interface. It can be concluded that the surface becomes rougher. However, the present study gives contrary results in terms of the specified feed rates. These findings show that more lubricant film breakage occurs in the selected feeds. Increasing the feed rate in the selected range decreases the SR of the mild steel sheets. Table 4 shows that the feed rate has low effect on the SR of this type of steel, this is very similar to what is observed experimentally about the spindle speed.

Taguchi designs are primarily intended to study the main effects of factors. Occasionally, you might want to study some 2-way interactions. Figure 6 shows 2-way interaction plots, representing the process parameters' effect on the SR. It is evident that larger tool diameter and tool's smaller vertical movement gives a better surface quality.

\subsection{Analysis of variance (ANOVA)}

The ANOVA is a statistical method used for testing the differences between two or more means. By using the analysis of variance, as well as the means response table, the most effective factor in the experimental tests can be determined. Moreover, the participation percentage of each variable (factor contribution) in the response can be evaluated. Table 5 depicts the ANOVA results of the samples. DF represents the Degree of Freedom, Seq.SS is the sequential sum of squares, Adj.SS is the adjusted sum of squares, and Adj.MS is the adjusted mean square. $F$-value is the ratio of the source variance to the error variance. $P$ value is used to evaluate the effect of each parameter on the output. The confidence level of $95 \%$ is proposed here, regarding which corresponding analysis is carried out. The $P$-value less than 0.05 means that the output is significantly affected by the parameter. Moreover, as shown in Table 5, the contribution indicates the participation percentage of each process variable in the SR of the mild steel sheets in the SPIF. As shown in Table 5 , the vertical step is the most effective parameter for $R_{a}$ of the mild steel sheets in the experiments; its contribution is $55.88 \%$. The next effective parameter is the tool diameter size with the contribution of $33.13 \%$. The results are consistent with factor ranking, shown 


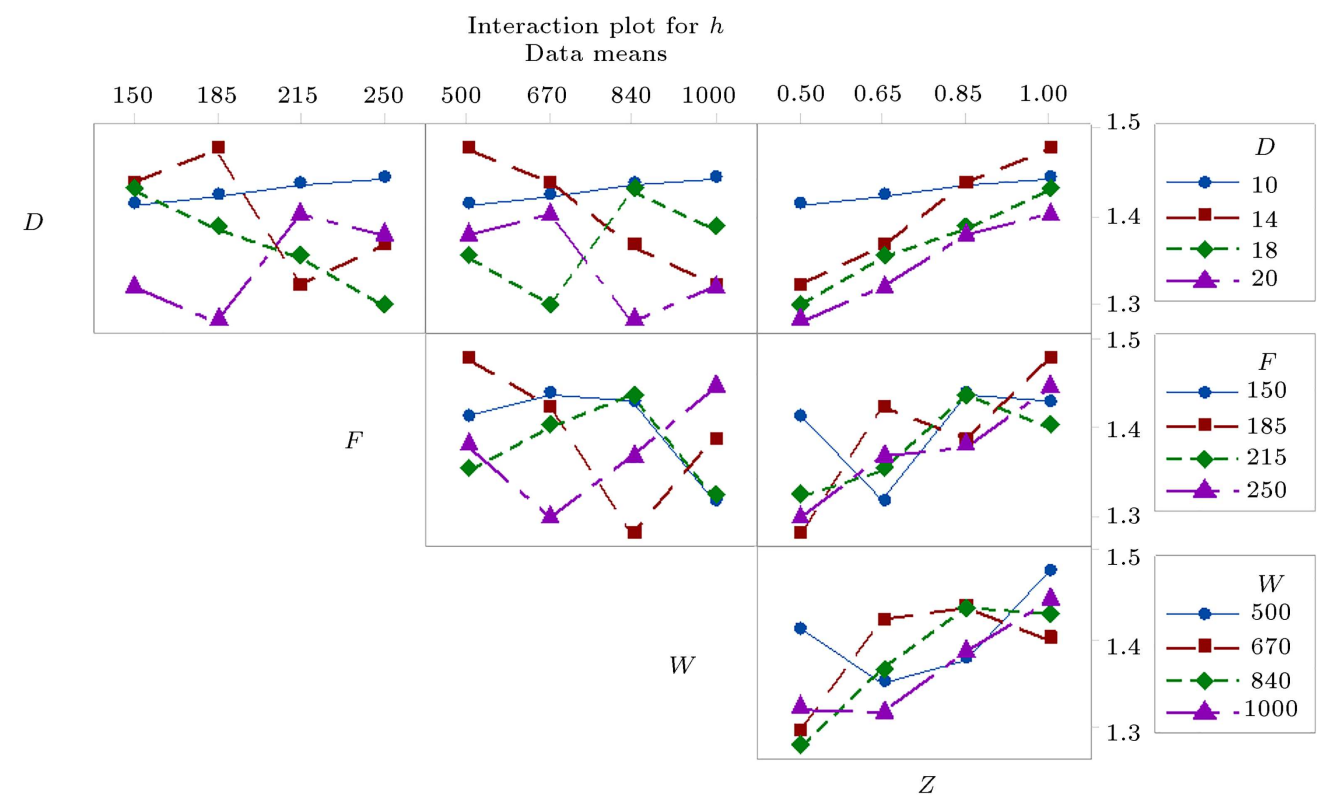

Figure 6. Two-way interaction plots of the effect of process parameters on the SR.

Table 5. Analysis of variance of $R_{a}$ of the mild steel sheets in the Single-Point Incremental Forming (SPIF) experiments of forming the elongated cone.

\begin{tabular}{cccccccc}
\hline Source & DF & Seq SS & Contribution & Adj SS & Adj MS & $\boldsymbol{F}$-value & $\boldsymbol{P}$-value \\
\hline$D$ & 3 & 0.016798 & $33.13 \%$ & 0.016798 & 0.005599 & 36.20 & 0.007 \\
$F$ & 3 & 0.001910 & $3.77 \%$ & 0.001910 & 0.000637 & 4.12 & 0.138 \\
$W$ & 3 & 0.003201 & $6.31 \%$ & 0.003201 & 0.001067 & 6.90 & 0.074 \\
$Z$ & 3 & 0.028331 & $55.88 \%$ & 0.028331 & 0.009444 & 61.06 & 0.003 \\
Error & 3 & 0.000464 & $0.92 \%$ & 0.000464 & 0.000155 & - & - \\
Total & 15 & 0.050704 & $100.00 \%$ & - & - & - & - \\
\hline
\end{tabular}

in Table 4. Table 5 illustrates that the spindle speed and the feed rate have no significant effect on the SR of mild steel sheets with the contribution of less than $10 \%$.

\subsection{Determination of the optimum surface roughness}

In the Taguchi design, to optimize the input variables, the signal-to-noise $(S / N)$ ratio is employed. Determining the levels of the process parameters' effect on the response, the optimum conditions are defined. The optimum level of the parameters has the largest $S / N$ ratio. The $S / N$ ratio is divided into three groups:

1. Nominal is the better case;

2. Smaller is the better one;

3. Larger is the better case [24].

This study aims to minimize the surface roughness; hence, the-smaller-the-better method is utilized based on Eq. (2) [25]:

$$
S / N \text { ratio }=10 \log _{10}\left(\frac{1}{n} \sum_{i=1}^{n} y_{i}^{2}\right),
$$

where $y_{i}$ is $R_{a}$, measured by the stylus instruments (see Figure 4 ), and $n$ denotes the number of observations on a particular product. As shown in Table 6, the optimum level of the input variables (the largest $S / N$ ratio), is $D_{4}, F_{4}, W_{4}$, and $Z_{1}$. Here the lower $R_{a}$ and the formed mild steel sheets' SR are considered. It means that the minimum $R_{a}$ represents the optimum condition, when the fourth level of the tool diameter $\left(D_{4}\right)$, the fourth level of the feed rate $\left(F_{4}\right)$, the fourth level of the spindle speed $\left(W_{4}\right)$, and the first level of the vertical step $\left(Z_{1}\right)$ are selected. Based on Table 4 , surface roughness rates at the levels of $D_{4}, F_{4}, W_{4}$, and $Z_{1}$ are $1.343,1.371,1.367$, and $1.327 \mu \mathrm{m}$, respectively. The optimum $R_{a}$ is predicted [26] as in Eq. (3): 
Table 6. Table of responses for the signal-to-noise ratios in the-smaller-the-better case.

\begin{tabular}{ccccc}
\hline Level & $\boldsymbol{D}$ & $\boldsymbol{F}$ & $\boldsymbol{W}$ & $\boldsymbol{Z}$ \\
\hline 1 & -3.097 & -2.911 & -2.947 & -2.453 \\
2 & -2.914 & -2.851 & -2.849 & -2.695 \\
3 & -2.704 & -2.777 & -2.771 & -2.978 \\
4 & -2.559 & -2.735 & -2.708 & -3.149 \\
Delta & 0.538 & 0.177 & 0.240 & 0.697 \\
Rank & 2 & 4 & 3 & 1 \\
\hline \multicolumn{5}{c}{} \\
$R_{a}=D_{4}+F_{4}+W_{4}+Z_{1}-3 T$ \\
$=1.343+1.371+1.367+1.327-3 \times 1.384$ \\
$=1.206 \mu \mathrm{m}$,
\end{tabular}

where $T$ is the average of the surface roughness responses (see Table 3 ).

\subsection{Confirmation test}

To detect the difference between the experimental tests and the mathematical modeling, a validation test was performed at a specified level. Taking the following conditions as the indicators of optimum condition, the surface best quality with the minimum roughness (optimum condition) was determined:

- The tool diameter of $20 \mathrm{~mm}\left(D_{4}\right.$ : The fourth level of the tool diameter);

- Feed rate of $250 \mathrm{~mm} / \mathrm{min}\left(F_{4}\right.$ : The fourth level of the feed rate);

- Spindle speed of $1000 \mathrm{rpm}\left(W_{4}\right.$ : The fourth level of the spindle speed);

- Vertical step of $0.5 \mathrm{~mm}\left(Z_{1}\right.$ : The first level of the vertical step).

Respecting these input parameters, the difference value between the experiment and predicted optimum level was revealed as follow: the $R_{a}$ of the experiment with factors of the optimum condition is $1.264 \mu \mathrm{m}$ and less than 5\% difference between the experiment and predicted optimum level was revealed. Therefore, the optimum level can be revised because of the small difference between the experimental results and predicted value. Figure 7 shows the surface quality of two different samples, including the optimized formed blank. The results illustrate that the SR of the mild steel sheets is decreased significantly under optimal condition. In addition, better surface quality and smoother surface result from a decrease of the vertical step size and an increase of the tool diameter.

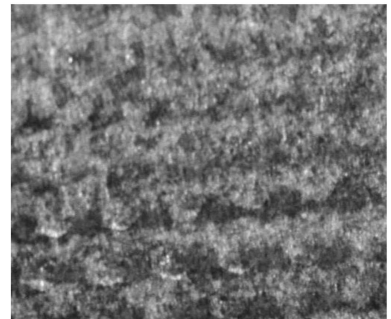

(a)

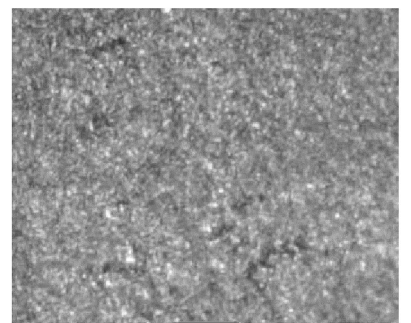

(b)
Figure 7. Surface quality of two different specimens of mild steel sheets formed in the Single-Point Incremental Forming (SPIF) process: (a) $D=10 \mathrm{~mm}$ and $Z=1 \mathrm{~mm}$ and (b) specimen with the optimum condition: $D=20 \mathrm{~mm}$ and $Z=0.5 \mathrm{~m}$.

\section{Conclusion}

In this paper, the SR of the mild steel sheets was investigated, using the Taguchi $L_{16}$ orthogonal array and ANOVA. The effect of the process parameters, i.e., the feed rate, tool diameter, vertical step and spindle speed, was studied through the Single-Point Incremental Forming (SPIF) process of forming an elongated hole. Arithmetic average roughness $\left(R_{a}\right)$ was employed to evaluate the effect of input variables on the roughness of the final formed blanks. The results of this study are as follows:

- Tool vertical movement has the greatest impact on the SR of the mild steel sheets. Increasing the vertical step results in the increase of $R_{a}$ and a rough surface appears on the formed specimens;

- Increasing the tool diameter leads to reduction of $R_{a}$ and smoother surface of the mild steel sheets in the SPIF;

- The ANOVA test results approved that the speed of the spindle and the feed rate have no significant effect on the SR of the mild steel sheets;

- According to the graphs, tables and the provided experimental results, it was found that a better surface quality can be achieved with a lower vertical movement and a larger tool diameter;

- The tool optimum condition characterized by the diameter of $20 \mathrm{~mm}$, feed rate of $250 \mathrm{~mm} / \mathrm{min}$, rotation speed of $1000 \mathrm{rpm}$ and step size of $0.5 \mathrm{~mm}$ is achieved by the Taguchi technique and was validated experimentally.

\section{References}

1. Jeswiet, J. and Hagan, E. "Rapid proto-typing of a headlight with sheet metal", 9th International Conference on Sheet Metal Forming, Leuven, Belgium, pp. 165-170 (2001).

2. Leach, D., Green, A.J., and Bramley, A.N. "A new incremental sheet forming process for small batch 
and prototype parts", 9th International Conference on Sheet Metal Forming, Leuven, Belgium, pp. 211-218 (2001).

3. Filice, L., Fratini, L., and Micari, F. "Analysis of material formability in incremental forming", CIRP Annals- Manufacturing Technology, 51(1), pp. 199202 (2002).

4. Powell, N. and Andrew, C. "Incremental forming of flanged sheet metal components without dedicated dies", Proceedings of the Institution of Mechanical Engineers, Part B: Journal of Engineering Manufacture, 206(1), pp. 41-47 (1992).

5. Matsubara, S. "Incremental backward bulge forming of a sheet metal with a hemispherical tool", Journal of the Japan Society for Technology of Plasticity, 35(406), pp. 1311-1316 (1994).

6. Silva, M.B. and Martins, P.A. "Two-point incremental forming with partial die: theory and experimentation", Journal of Material Engineering Performance, 22(4), pp. 1018-1027 (2013).

7. Hagan, E. and Jeswiet, J. "Analysis of surface roughness for parts formed by computer numerical controlled incremental forming", Proceedings of the Institution of Mechanical Engineers, Part B: Journal of Engineering Manufacture, 218(10), pp. 1307-1312 (2004).

8. Cerro, I., Maidagan, E., Arana, J., et al. "Theoretical and experimental analysis of the dieless incremental sheet forming process", Journal of Materials Processing Technology, 177(1-3), pp. 404-408 (2006).

9. Durante, M., Formisano, A., Langella, A., et al. "The influence of tool rotation on an incremental forming process", Journal of Materials Processing Technology, 209(9), pp. 4621-4626 (2009).

10. Hamilton, K. and Jeswiet, J. "Single point incremental forming at high feed rates and rotational speeds: Surface and structural consequences", CIRP AnnalsManufacturing Technology, 59(1), pp. 311-314 (2010).

11. Bhattacharya, A., Maneesh, K., Venkata Reddy, N., et al. "Formability and surface finish studies in single point incremental forming", Journal of Manufacturing Science and Engineering, 133(6), pp. 061020-1061020-8 (2011).

12. Lu, B., Fang, Y., Xu, D.K., et al. "Mechanism investigation of friction-related effects in single point incremental forming using a developed oblique rollerball tool", International Journal of Machine Tools \& Manufacture, 85, pp. 14-29 (2014).

13. Echrif, S.B.M. and Hrairi, M. "Significant parameters for the surface roughness in incremental forming process", Materials and Manufacturing Processes, 29(6), pp. 697-703 (2014).

14. Gulati, V., Aryal, A., and Katyal, P. "Process parameters optimization in single point incremental forming", Journal of the Institution of Engineers (India): Series $C, \mathbf{9 7}(2)$, pp. 185-193 (2016).
15. Yao, Z., Li, Y., Yang, M., et al. "Parameter optimization for deformation energy and forming quality in single point incremental forming process using response surface methodology", Journal of Advances in Mechanical Engineering, 9(7), pp. 1-15 (2017).

16. Taherkhani, A., Basti, A., and Nariman Zadeh, N. "Achieving maximum dimensional accuracy and surface quality at the shortest possible time in single-point incremental forming via multi-ob jective optimization", Proceedings of the Institution of Mechanical Engineers, Part B: Journal of Engineering Manufacture, 233(3), pp. 900-913 (2018).

17. Asghari, A., Sarband, A., and Habibnia, M. "Optimization of multiple quality characteristics in twopoint incremental forming of aluminum 1050 by grey relational analysis", Proceedings of the Institution of Mechanical Engineers, Part C: Journal of Mechanical Engineering Science, 203, pp. 1989-1996 (2017).

18. Khalkhali, A., Noraie, H., and Sarmadi, M. "Sensitivity analysis and optimization of hot-stamping process of automotive components using analysis of variance and Taguchi technique", Proceedings of the Institution of Mechanical Engineers, Part E: Journal of Process Mechanical Engineering, 231(4), pp. 732-746 (2016).

19. Tang, L., Ma, Y., Wang, J., et al. "Robust parameter design of supply chain inventory policy considering the uncertainty of demand and lead time", Scientia Iranica, 26(5), pp. 1-34 (2018). DOI: $10.24200 /$ sci.2018.5205.1217

20. Roy, R.K., A Primer on the Taguchi Method, Society of Manufacturing Engineers (SME), Michigan, USA (2010).

21. Malkin, S. and Guo, C., Grinding Technology-Theory and Applications of Machining with Abrasives, Industrial Press, New York, USA (2008).

22. Shojaeefard, M.H., Kalkhali, A., and Shahbaz, S.O. "Analysis and optimization of the surface waviness in the single-point incremental sheet metal forming", Proceedings of the Institution of Mechanical Engineers, Part E: Journal of Process Mechanical Engineering, 233(4), pp. 919-925 (2018).

23. Moghaddam, M. and Kolahan, F. "Using combined artificial neural network and particle swarm optimization algorithm for modeling and optimization of electrical discharge machining process", Scientia Iranica, 27(3), pp. 1-22 (2019). DOI: $10.24200 /$ sci.2019.5152.1123

24. Mohammadi, S., Cheraghalikhani, A., and Ramezanian, R. "A joint scheduling of production and distribution operations in a flow shop manufacturing system", Scientia Iranica, Transactions E: Industrial Engineering, 25(2), pp. 911-930 (2018). 
25. Hemmati Far, M., Haleh, H., and Saghaeia, A. "A flexible cell scheduling problem with automated guided vehicles and robots under energy-conscious policy", Scientia Iranica, Transactions E: Industrial Engineering, 25(1), pp. 339-358 (2018).

26. Ross, P.J., Taguchi Techniques for Quality Engineering, McGraw-Hill, New York, USA (1988).

\section{Biographies}

Mohammad Hassan Shojaeefard, was born in 1950, in Jahrom, Iran. He successfully completed the BSc degree in Mechanical Engineering from Iran University of Science and Technology (IUST) in 1977. He also successfully attained an MSc degree in mechanical engineering from University of Birmingham, UK, in 1983. Professor Shojaeefard holds a PhD in Mechanical Engineering from University of Birmingham, UK since 1987. Now, he is the Professor and Head of Automotive Engineering Research Center (AERC) and Automotive
Engineering Department (AED) (IUST). The Specific topics of interests of Professor Shojaeefard is fluid dynamics, internal combustion engines and automotive engineering.

Abolfazl Khalkhali is the Associate Professor in School of Automotive Engineering, Iran University of Science and Technology (IUST). His BSc, MSc and $\mathrm{PhD}$ are in Mechanical Engineering. His expertise are automotive body structure analysis and design, finite element analysis, engineering optimization, reliabilitybased and robust design, and GMDH Neural Network.

Shahaboddin Shahbaz is a graduate of Iran University of Science and Technology (IUST) in 2019. His BSc is in Mechanical Engineering and MSc and $\mathrm{PhD}$ in Automotive Engineering. His interests are automotive body structure analysis and design, finite element analysis, sheet metal forming, engineering optimization, and incremental forming. 